\title{
Image Reconstruction with Prior Information in Electrical Resistance Tomography
}

\author{
Bong Seok Kim*, Sin Kim ${ }^{* *}$, Kyung Youn Kim ${ }^{* * * \star}$
}

\begin{abstract}
Electrical resistance tomography (ERT) has high temporal resolution characteristics therefore it is used as an alternative technique to visualize two-phase flows. The image reconstruction in ERT is highly non-linear and ill-posed hence it suffers from poor spatial resolution. In this paper, the inverse problem is solved with homogeneous data used as a prior information to reduce the condition number of the inverse algorithm and improve the spatial resolution. Numerical experiments have been carried out to illustrate the performance of the proposed method.
\end{abstract}

Key words: electrical resistance tomography, two-phase flow, prior information, ill-posedness, Gauss-Newton method

\section{Introduction}

Two-phase flows are of great interest in many engineering applications. For example, liquid-gas or liquid-vapor mixtures are encountered in condensers, evaporators, gas-liquid reactors and combustion systems[1]. The flow configuration of the two-phase mixture is important in the design and safe operation of such systems. For the visualization of two-phase flows, various tomographic techniques with noninvasive modalities have been developed, for example, gamma densitometry, ultrasonic imaging and nuclear magnetic resonance imaging.

* Clean Energy Convergence and Integration Center for Human Resources Training and Education, Jeju National University, Jeju 690-756, Korea

** Department of Nuclear and Energy Engineering, Jeju National University, Jeju 690-756, Korea

*** Department of Electronic Engineering, Jeju National University, Jeju 690-756, Korea

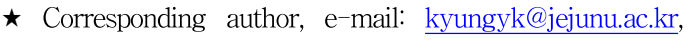
Tel: $+82-64-754-3664$

* This research was supported by the 2013 scientific promotion program funded by Jeju National University.

Manuscript received Jan. 10, 2014; revised Jan. 17, 2014; accepted Jan 20. 2014
Electrical resistance tomography (ERT) has been employed as an alternative technique to visualize two-phase flows[2], because it offers a high temporal resolution to monitor fast transient processes. While ERT has a strong potential for visualizing of two-phase fields, it still remains a challenging problem to improve the spatial resolution due to its non-linearity and ill-posedness.

In order to overcome a poor spatial resolution, Kim et al.[3] proposed a novel adaptive mesh grouping scheme with predefined thresholds to enhance the spatial resolution of the Gauss-Newton (GN) method. In this approach, best homogeneous resistivity value [4] was employed to determine the classification criterion from the resistivity profile estimated after several iterations. Kim et al.[5] proposed a novel image reconstruction technique to improve the spatial resolution by employing an adaptive threshold method to the iterative Gauss-Newton method. In their approach, an optimal threshold is automatically selected by Otsu's method[6] and then the adaptive threshold value is employed to separate the background from the target regions based on the resistivity profile estimated on every iteration.

Introducing prior information into ERT inverse 
solver can diminish the ill-posedness and thus can have improved reconstruction images[7]. In this perspective, few researchers have assumed conductivities of anamolies is constant and isotropic in two-phase flow aiming in locating the boundary of anamolies[8-10]. In the work of Kim et al.[11], as a prior information fixed structures inside the process vessel are considered as electrodes and resistivity values are assumed to be known for two-phase flow monitoring. Heikkinen et al.[12] estimated the volume fraction distribution with bulk volume fraction as prior information. Ill-posedness can also be reduced by regularization. Different regularization schemes are adopted with the ERT image reconstruction to mitigate the ill-posedness [4,13-14].

In this paper, prior information is homogeneous data inside a given domain. Implementing this prior information into the image reconstruction, more improved results could be made with the aid of ERT. As an inverse solver the iterative Gauss-Newton method incorporating prior information is employed to improve the spatial resolution. The main feature of the proposed method is to reduce the condition number of the inverse algorithm and diminish the ill-posedness in the inverse problem, and therefore enhance the spatial resolution. Numerical experiments have been carried out to illustrate the reconstruction performance of the proposed method.

\section{Forward Problem}

In ERT, currents are injected through the electrodes placed on the surface of a domain and the resulting voltages are measured across these electrodes. The forward problem is to compute the boundary voltages given the internal conductivity distribution and the applied currents.

When current $I_{l}$ is injected through the electrode on the surface $\partial \Omega$ and the conductivity distribution $\sigma$ is known, the electric potential $u$ in the domain $\Omega \in \mathbb{R}^{2}$ can be solved from the partial differential equation with the boundary conditions for the complete electrode model[15]

$\nabla \cdot \sigma \nabla u=0$ in $\Omega$ $u+z_{l} \sigma \frac{\partial u}{\partial \nu}=U_{l}$ on $e_{l}, l=1,2, \ldots, L$

$\int_{e_{l}} \sigma \frac{\partial u}{\partial \nu} d s=I_{l}$ on $e_{l}, l=1,2, \ldots, L$

$\sigma \frac{\partial u}{\partial \nu}=0$ off $e_{l}$

where $z_{l}$ denotes the effective contact impedance between the electrode and the surface, $U_{l}$ is the boundary voltage measured through the electrode $e_{l}$, $\nu$ is the outward unit normal and $L$ is the number of electrodes.

There are various data collection methods by which the currents are injected and the resulting voltages are measured[16]. Several ways of them are commonly used in two-dimensional imaging, for example adjacent method, opposite method and trigonometric method. In this paper, the adjacent method is employed, which has good sensitivity at the periphery but not good at the center because of the lower current density.

The finite element (FE) method is used to obtain the numerical solution of the governing equation. The domain is divided into a finite number of small triangular elements and it is assumed that the conductivity is constant within each element. The forward problem can be formulated as a system of linear equations, $\quad A b=f \quad$ where $A \in \mathbb{R}^{\left(N_{n}+L-1\right) \times\left(N_{n}+L-1\right)}$ denotes the system matrix, $b \in \mathbb{R}^{\left(N_{n}+L-1\right) \times 1} \quad$ is the forward solution, $f \in \mathbb{R}^{\left(N_{n}+L-1\right) \times 1}$ is the data vector that is a function of the injected currents and $N_{n}$ is the number of nodes. Details for the forward problem are given in the reference[7].

\section{Inverse Problem}

\subsection{Conventional iterative Gauss-Newton method}

In order to solve the non-linear ERT inverse problem, usually the GN method is employed to determine the resistivity distribution inside the domain. To overcome the ill-posedness of the ERT inverse problem, the following objective function with the regularization is formulated to minimize the error in the least-square sense 
$\Phi(\rho)=\frac{1}{2}\left\{\|U(\rho)-V\|^{2}+\alpha\|R \rho\|^{2}\right\}$

where $U(\rho)$ denotes the voltages calculated through the FE formulation, $V$ is the actual voltages measured across the electrodes, $\alpha$ and $R$ are the regularization parameter and matrix, respectively.

Taking the derivative and linearizing about a resistivity vector $\hat{\rho}_{i-1}$ at $(i-1)$ th iteration, the GN method can be obtained as

$$
\begin{aligned}
\hat{\rho}_{i}=\hat{\rho}_{i-1} & +\left[J_{i-1}^{T} J_{i-1}+\alpha R^{T} R\right]^{-1} \\
& \times\left[J_{i-1}^{T}\left(V-U_{i-1}\right)-\alpha R^{T} R \hat{\rho}_{i-1}\right]
\end{aligned}
$$

where $\quad J_{i-1} \equiv J\left(\hat{\rho}_{i-1}\right) \in \mathbb{R}^{L K \times N} \quad$ is the Jacobian matrix, $U_{i-1} \equiv U\left(\hat{\rho}_{i-1}\right) \in \mathbb{R}^{L K \times 1}, K$ is the number of measured patterns, $N$ is the number of elements and the regularization matrix $R \in \mathbb{R}^{N \times N}$ is used with a first-order discrete Gaussian smoothing operator. Here, when $i=1$, it is called one--step GN method.

The GN method is used as a standard inverse

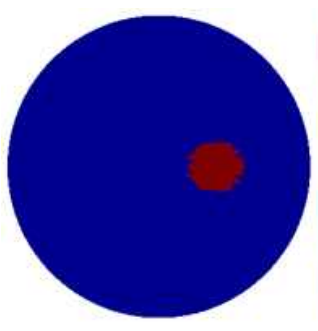

(a)

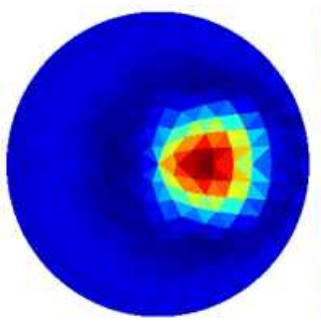

(e)
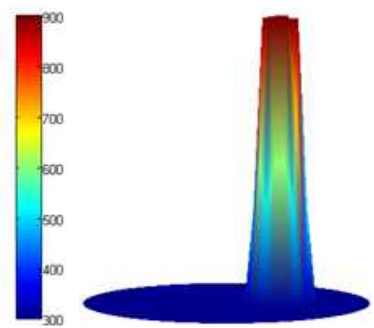

(b)
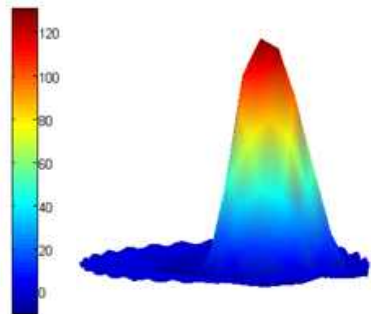

(f) algorithm for static scenarios of the ERT inverse problem. However, it sometimes meets the ill-posedness problem and fails to get the good spatial resolution in the presence of noise. In this paper, to mitigate the ill-posedness and improve the spatial resolution, the homogeneous data as a prior information is employed in the inverse solver, which is available to get in advance in the two-phase flow fields.

\subsection{Iterative Gauss-Newton method with prior} information

For the ERT reconstruction problem the following objective function with prior information can be formulated to minimize the error

$\Phi(\rho)=\frac{1}{2}\left\{\|U(\rho)-V\|^{2}+\alpha\left\|R\left(\rho-\rho^{*}\right)\right\|^{2}\right\}$

where $\rho^{*}$ is prior information.

Taking the derivative and linearizing about a resistivity vector $\hat{\rho}_{i-1}$ at $(i-1)$ th iteration, the GN method with prior information can be obtained

Fig. 1. True and reconstructed images: (a) $2 \mathrm{D}$ plot for the true resistivity distribution, (b) the corresponding 3D representation, (c) 2D plot for the reconstructed static image using one-step GN method, (d) the corresponding $3 \mathrm{D}$ representation, (e) 2D plot for the reconstructed difference image between inhomogeneous and prior homogeneous data using one-step GN method, (f) the corresponding 3D representation, (g) 2D plot after image segmentation and $(\mathrm{h})$ the corresponding $3 \mathrm{D}$ representation.

그림 1. 원래 영상과 복원 영상: (a) 원래 저항률 분포에 대한 $2 \mathrm{D}$ 영상, (b) 이에 상응하는 $3 \mathrm{D}$ 영상, (c) one-step GN 방법을 사용해 복원된 $2 \mathrm{D}$ 정적 영상, $(\mathrm{d})$ 이에 상응하는 $3 \mathrm{D}$ 영상, $(\mathrm{e})$ 균질 데이터와 비균질 데이터를 사용해 복원된 $2 \mathrm{D}$ 차 이 영상, (f) 이에 상응하는 $3 \mathrm{D}$ 영상, $(\mathrm{g})$ 영상 분할 후의 $2 \mathrm{D}$ 영상, $(\mathrm{h})$ 이에 상응하는 $3 \mathrm{D}$ 영상 


$$
\begin{aligned}
\hat{\rho}_{i}=\hat{\rho}_{i-1} & +\left[J_{i-1}^{T} J_{i-1}+\alpha R^{T} R\right]^{-1} \\
\times & {\left[J_{i-1}^{T}\left(V-U_{i-1}\right)-\alpha R^{T} R\left(\hat{\rho}_{i-1}-\rho^{*}\right)\right] }
\end{aligned}
$$

Here, the term $\alpha R^{T} R\left(\hat{\rho}_{i-1}-\rho^{*}\right)$ can be enforced to be a zero vector by choosing $\rho^{*}=\hat{\rho}_{i-1}$ as prior information, then we have the simplified GN method for updating the resistivity vector as follows

$\hat{\rho}_{i}=\hat{\rho}_{i-1}+\left[J_{i-1}^{T} J_{i-1}+\alpha R^{T} R\right]^{-1} J_{i-1}^{T}\left(V-U_{i-1}\right)$

To verify the effect of prior information of homogeneous background in a circular domain, the one-step GN method is employed to reconstruct the simulated scenario in the presence of noise, as an example of visualization of two-phase flows. True distribution of internal resistivity can be viewed in $2 \mathrm{D}$ and $3 \mathrm{D}$ representation as shown in figures 1 (a) and $1(\mathrm{~b})$, respectively. The anomaly with circular shape is assumed to be static during the time to collect a full set of independent measurement data. The reconstructed image of internal resistivity distribution using one-step GN method is shown in figure $1(\mathrm{c})$ as $2 \mathrm{D}$ representation and figure $1(\mathrm{~d})$ shows its 3D representation. From figures 1(c) and 1(d), it can be noticed that the target is distinguished from the background. However, the image is blurred, especially the background distribution is not uniform because of noise as shown in figure $1(\mathrm{~d})$. The spatial resolution is poor while using conventional GN method as inverse solver.

Use of prior homogeneous resistivity distribution can improve the spatial resolution of the reconstructed image. Moreover, it reduces the condition number and ill-posedness of the inverse solver. Figure 1(e) shows the difference image between reconstructed inhomogenous and homogenous resistivity distributions. It can be noticed that the target region is more apparent compared to figure 1 (c) and the background region in figure $1(\mathrm{f})$ is even. The reconstructed resistivity distribution using the prior homogenous data still contains blurred regions and due to regularization used in inverse problem the element resistivity values are smoothened out.

Image segmentation is done to improve the spatial resolution of the reconstructed results with prior information. Region enclosed by the maximum and background resistivities are determined from the resistivity distribution plot. The region is divided into three equal segments with two threshold levels. The maximum resistivity value corresponds to the target resistivity value and the three regions correspond to the pixels near to the target and background. The pixels that have value less than the lower threshold level are assigned as background elements and the pixels that have value more than the lower threshold value are assigned as target elements. Therefore after image segmentation as seen from figures $1(\mathrm{~g})$ and $1(\mathrm{~h})$ more uniform distribution is observed in background and target regions thus improving spatial resolution.

The proposed iterative GN method with prior information (GNPI) is described in detail in the following steps.

(i) Find an initial guess $\hat{\rho}_{0}$ that is the best homogeneous resistivity approximation in the least-square sense[4].

(ii) Compute the boundary voltage $U\left(\hat{\rho}_{0}\right)$ and the Jacobian matrix $J\left(\hat{\rho}_{0}\right)$ with the initial resistivity $\hat{\rho}_{0}$.

(iii) Estimate and save the resistivity vector $\left(\hat{\rho}_{\mathrm{homo}_{\mathrm{o}}}\right)$ for the homogeneous data using the one-step GN method in eq. (9).

(iv) Set $i=1$.

(v) Update the resistivity vector using the GN method in eq. (9).

(vi) Compute the resistivity difference between inhomogeneous and homogeneous data.

$\delta \hat{\rho}=\hat{\rho}_{i}-\hat{\rho}_{\text {homo }}$

where $\hat{\rho}_{i}$ and $\hat{\rho}_{\text {homo }}$ are inhomogeneous and homogeneous estimated resistivity vectors, respectively.

(vii) Find an index vector $d \in \mathbb{R}^{N_{d} \times 1}$ for the background elements.

$d=$ find_index $(\hat{\rho} \leq \max (\delta \hat{\rho}) / 3)$ if $\rho_{\text {bac }}<\rho_{\text {tar }}(11)$

where $N_{d}$ is the number of background indices, $\rho_{\text {bac }}$ 
and $\rho_{\text {tar }}$ denote background and target resistivity values, respectively, which could be approximately known from prior information in a given domain.

(viii) Modify the updated resistivity vector $\hat{\rho}_{i}$ with the background index as follows:

$\hat{\rho}_{i}(d)=\overline{\hat{\rho}}_{\text {homo }}$

where $\overline{\hat{\rho}}_{\text {homo }}$ represents the mean value of $\hat{\rho}_{\text {homo }}$.

(ix) Modify the regularization matrix in eq. (9) based on the background index, that is, the standard Tikhonov regularization is employed only for the background elements as follows[5]:

$\widetilde{R}=R$

$\widetilde{R}(d,:)=0$

for $j=1: N_{d}$

$$
\widetilde{R}(d(j), d(j))=1
$$

end

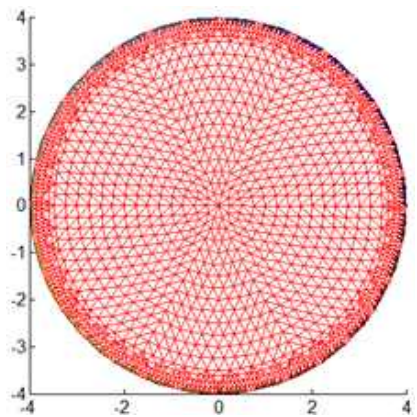

(a)

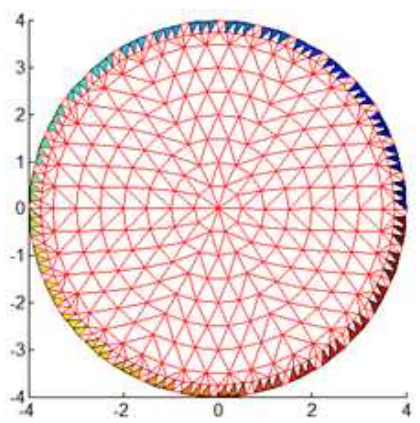

(b)

Fig. 2. The FE meshes: (a) forward fine mesh and (b) inverse coarse mesh. The colored regions in the boundary represent 32 electrodes.

그림 2. 유한요소 메쉬: (a) 정문제를 위한 조밀한 메쉬, (b) 역문제를 위한 성긴 메쉬. 경계면의 색 영역들은 32 개의 전극들을 의미한다. where $\widetilde{R}$ denotes the modified regularization matrix.

(x) Compute the boundary voltage $U\left(\hat{\rho}_{i}\right)$ and the Jacobian matrix $J\left(\hat{\rho}_{i}\right)$ with the modified resistivity vector $\hat{\rho}_{i}$.

(xi) Set $i=i+1$ and replace $R$ with $\widetilde{R}$ in eq. (9) and go to step $(\mathrm{v})$.

\section{Results}

The performance of the proposed method was evaluated using numerical data, and the results were compared with the conventional GN method.

A circular domain was used in this study, which could be considered as a model for the cross-section of an industrial process pipe. In order to describe the resistivity distribution inside the domain, two different FE meshes were employed in the forward and inverse problems so that the inverse crime[17] was avoided. For the numerical data we computed boundary voltages with the FE fine mesh shown in figure 2(a).

For the forward computations a fine mesh was generated with 3104 elements and 1681 nodes as shown in figure $2(\mathrm{a})$. In the inverse computations the coarse mesh with 776 elements and 453 nodes as shown in figure 2(b) was used to estimate the resistivity distribution. Adjacent current patterns were injected into the domain of $4 \mathrm{~cm}$ in radius through 32 electrodes in both numerical and experimental studies.

In order to generate the simulated noisy data, we computed the forward solver and a zero-mean Gaussian-distributed random noise with $1 \%$ standard deviation was added to the calculated voltages.

The geometry of the numerical phantom assumed was as follows: radius $4 \mathrm{~cm}$, width of the electrode $0.6 \mathrm{~cm}$ and the amplitude of the currents was 10 $\mathrm{mA}$. The resistivity value of the background was $300 \Omega \mathrm{cm}$ and the target resistivity value was set to $900 \Omega \mathrm{cm}$.

Three different scenarios were considered to test the reconstruction performance of the proposed algorithm according to the different regularization parameters. Numerical simulations were performed 


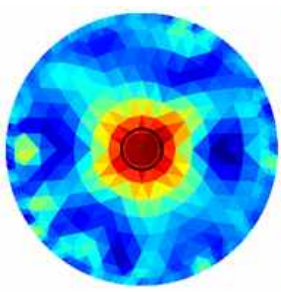

(a)

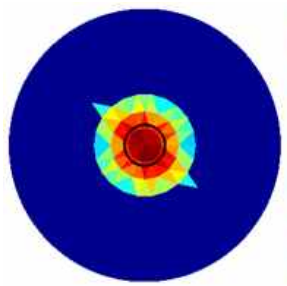

(d)
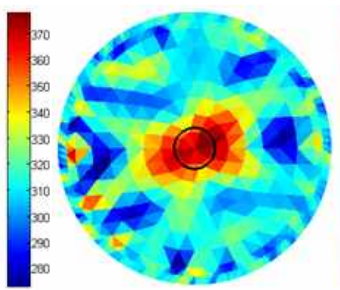

(b)
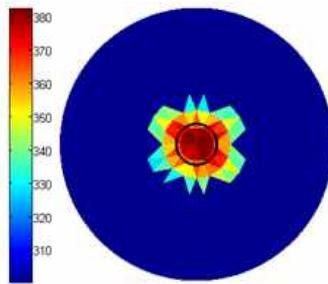

(e)
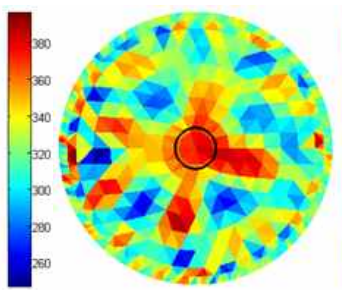

(c)

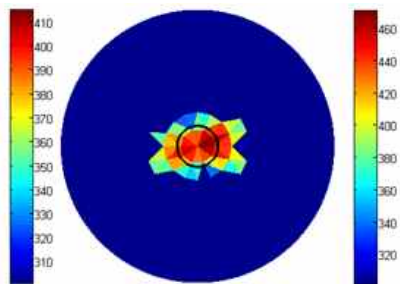

(f)

Fig. 3. Reconstructed images for case 1: (a) image by GN $\left(\alpha=1 \times 10^{-7}\right)$, (b) image by GN $\left(\alpha=1 \times 10^{-8}\right)$, (c) image by GN $\left(\alpha=1 \times 10^{-9}\right)$, (d) image by GNPI $\left(\alpha=1 \times 10^{-7}\right)$, (e) image by GNPI $\left(\alpha=1 \times 10^{-8}\right)$ and (f) image by GNPI $\left(\alpha=1 \times 10^{-9}\right)$. The black circles in the images represent the true position of one centered target.

그림 3. 경우 1 에 대한 복원 영상: (a) GN 방법에 의한 영상 $\left(\alpha=1 \times 10^{-7}\right)$, (b) GN 방법에 의한 영상 $\left(\alpha=1 \times 10^{-8}\right)$, (c) $\mathrm{GN}$ 방법에 의한 영상 $\left(\alpha=1 \times 10^{-9}\right)$, (d) GNPI 방법에 의한 영상 $\left(\alpha=1 \times 10^{-7}\right)$, (e) GNPI 방법에 의한 영상 $\left(\alpha=1 \times 10^{-8}\right)$, (f) GNPI 방법에 의한 영상 $\left(\alpha=1 \times 10^{-9}\right)$. 영상 내의 검은 색 원들은 1 개 표적의 원래 위치를 나 타낸다.

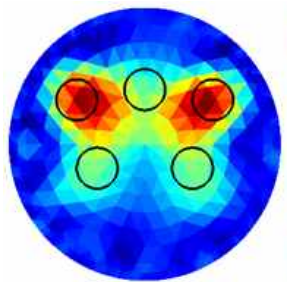

(a)

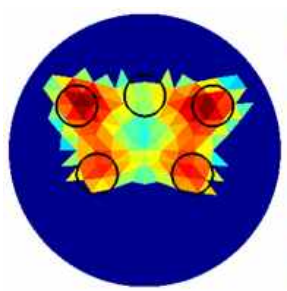

(d)

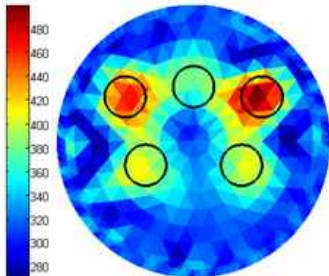

(b)

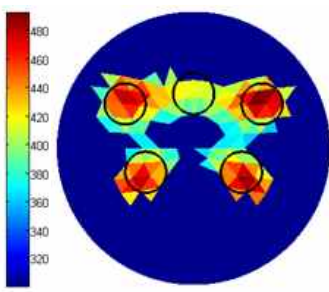

(e)

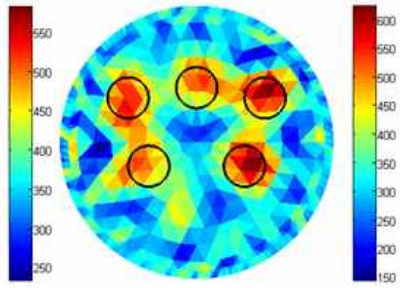

(c)

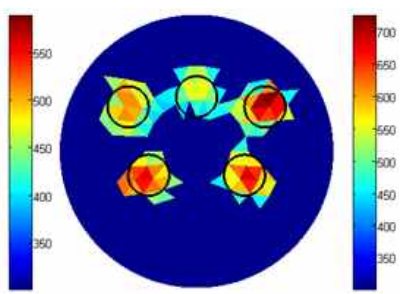

(f)

Fig. 4. Reconstructed images for case 2: (a) image by GN $\left(\alpha=1 \times 10^{-7}\right)$, (b) image by GN $\left(\alpha=1 \times 10^{-8}\right)$, (c) image by GN $\left(\alpha=1 \times 10^{-9}\right)$, (d) image by GNPI $\left(\alpha=1 \times 10^{-7}\right)$, (e) image by GNPI $\left(\alpha=1 \times 10^{-8}\right)$ and (f) image by GNPI $\left(\alpha=1 \times 10^{-9}\right)$. The black circles in the images represent the true positions of five targets.

그림 4. 경우 2에 대한 복원 영상: (a) GN 방법에 의한 영상 $\left(\alpha=1 \times 10^{-7}\right)$, (b) GN 방법에 의한 영상 $\left(\alpha=1 \times 10^{-8}\right)$, (c) $\mathrm{GN}$ 방법에 의한 영상 $\left(\alpha=1 \times 10^{-9}\right)$, (d) GNPI 방법에 의한 영상 $\left(\alpha=1 \times 10^{-7}\right)$, (e) GNPI 방법에 의한 영상 $\left(\alpha=1 \times 10^{-8}\right)$, (f) GNPI 방법에 의한 영상 $\left(\alpha=1 \times 10^{-9}\right)$. 영상 내의 검은 색 원들은 5 개 표적들의 원래 위치를 나타낸다. 
with several targets having a circular shape of radius $0.6 \mathrm{~cm}$. Case 1 is for single circular target placed at the center of the domain. Multiple targets located inside the domain are considered in case 2 (five targets) and case 3 (seven targets).

Figure 3 shows the reconstructed images for case 1. The first and second rows in figure 3 show the reconstructed images after 10 iterations using the conventional GN method and the GNPI method, respectively, according to the different regularization parameters, i.e., $\alpha=1 \times 10^{-7} \quad$ (first column), $\alpha=1 \times 10^{-8}$ (second column) and $\alpha=1 \times 10^{-9}$ (third column). In the first row, according to decreasing the regularization parameter, the reconstructed

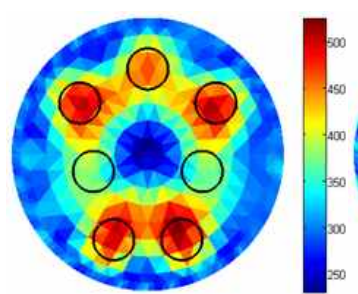

(a)

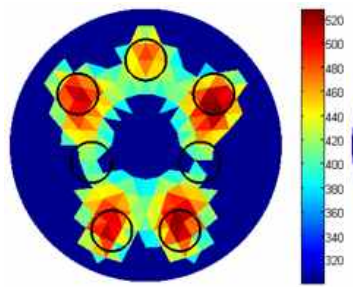

(d)

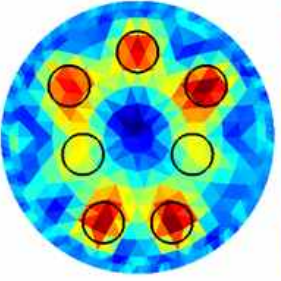

(b)

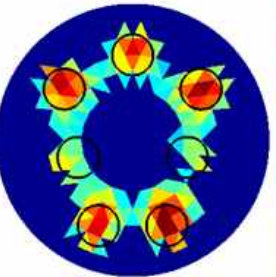

(e)

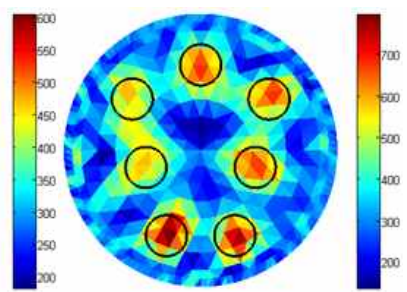

(c)

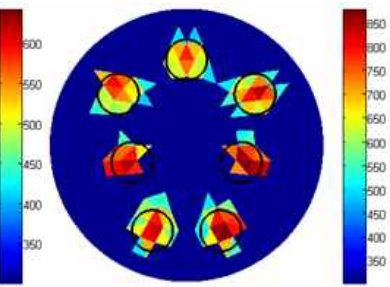

(f)

Fig. 5. Reconstructed images for case 3: (a) image by GN $\left(\alpha=1 \times 10^{-7}\right)$, (b) image by GN $\left(\alpha=1 \times 10^{-8}\right)$, (c) image by GN $\left(\alpha=1 \times 10^{-9}\right)$, (d) image by GNPI $\left(\alpha=1 \times 10^{-7}\right)$, (e) image by GNPI $\left(\alpha=1 \times 10^{-8}\right)$ and (f) image by GNPI $\left(\alpha=1 \times 10^{-9}\right)$. The black circles in the images represent the true positions of seven targets.

그림 5. 경우 3 에 대한 복원 영상: (a) GN 방법에 의한 영상 $\left(\alpha=1 \times 10^{-7}\right)$, (b) GN 방법에 의한 영상 $\left(\alpha=1 \times 10^{-8}\right)$, (c) $\mathrm{GN}$ 방법에 의한 영상 $\left(\alpha=1 \times 10^{-9}\right)$, (d) GNPI 방법에 의한 영상 $\left(\alpha=1 \times 10^{-7}\right)$, (e) GNPI 방법에 의한 영상 $\left(\alpha=1 \times 10^{-8}\right)$, (f) GNPI 방법에 의한 영상 $\left(\alpha=1 \times 10^{-9}\right)$. 영상 내의 검은 색 원들은 7 개 표적들의 원래 위치를 나 타낸다.

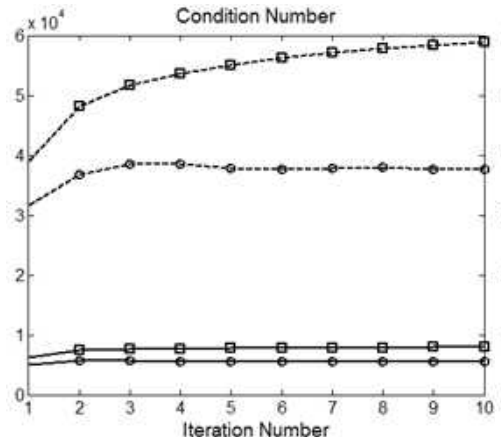

(a)

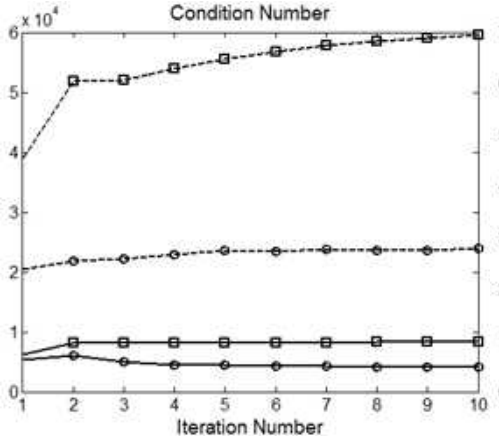

(b)

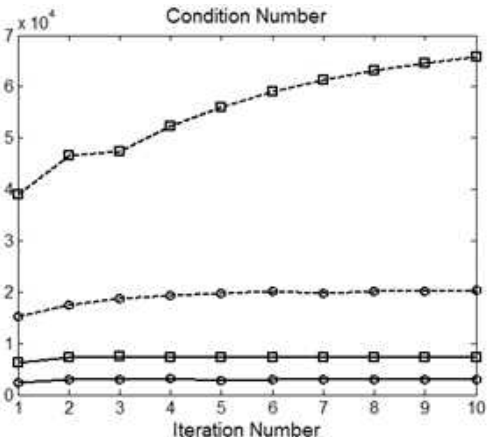

(c)

Fig. 6. Condition numbers in two inverse algorithms used for (a) case 1, (b) case 2 and (c) case 3. GN ( $\square$ ) and GNPI (-). The regularization parameter, $\alpha=1 \times 10^{-8}$ (solid line) and $\alpha=1 \times 10^{-9}$ (dashed line).

그림 6. 두 역문제 알고리즘들의 상태수 (a) 경우 1 , (b) 경우 2, (c) 경우 3. GN ( $\square$ )과 GNPI (- - ). 조정 인자, $\alpha=1 \times 10^{-8}$ (굵은 선)과 $\alpha=1 \times 10^{-9}$ (점선). 
images by the GN method have poor resolution because of noise effect. However, in the second row, the target is reconstructed with good accuracy by the proposed method. Moreover, the GNPI

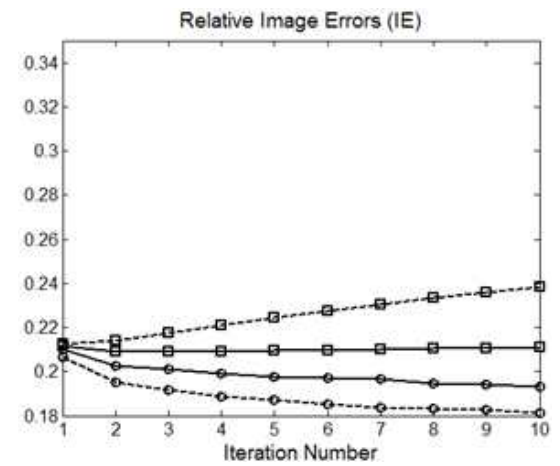

(a)

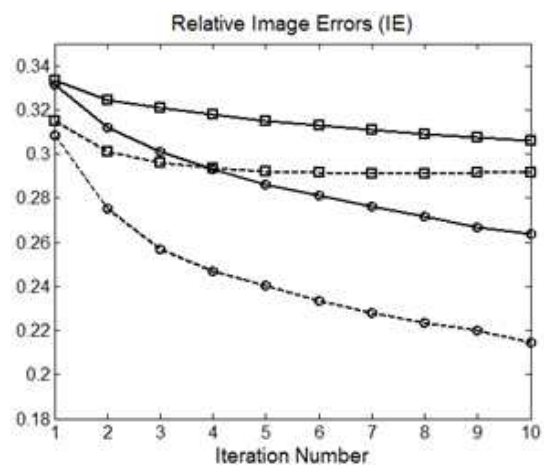

(c)

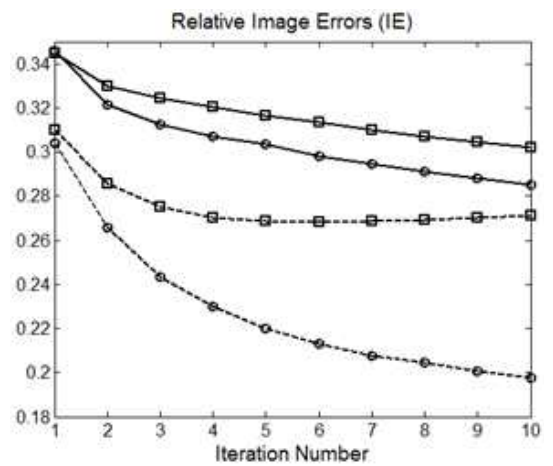

(e) images have even background resistivity distribution whose value is close to the true one. It is noted that the reconstructed image by the GNPI method has better spatial resolution compared to the GN

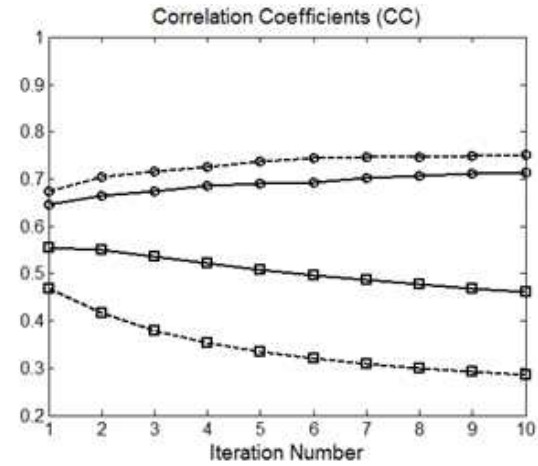

(b)

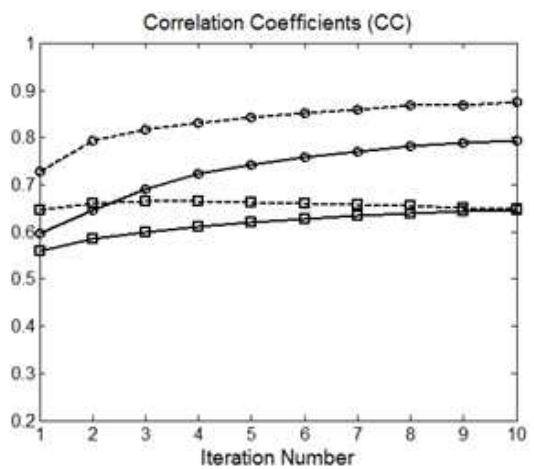

(d)

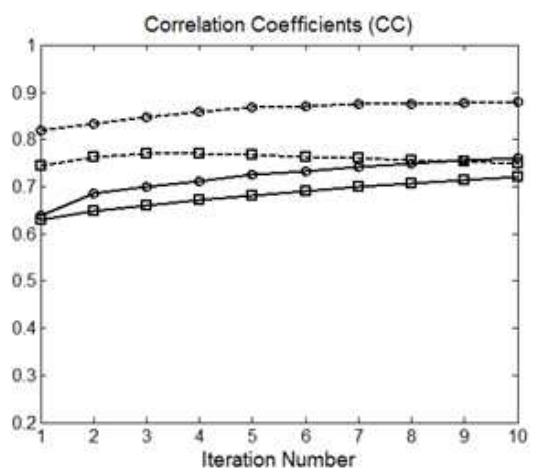

(f)

Fig. 7. Relative image errors (IE) and correlation coefficients (CC) for cases 1 to 3: (a) IE for case 1, (b) CC for case 1, (c) IE for case 2, (d) CC for case 2, (e) IE for case 3 and (f) CC for case 3. GN ( $\square$ ) and GNPI ( $\bigcirc$ ). The regularization parameter, $\alpha=1 \times 10^{-8}$ (solid line) and $\alpha=1 \times 10^{-9}$ (dashed line).

그림 7. 경우 1 에서 경우 3 까지의 상대적 영상 오차 $(\mathrm{IE})$ 와 상관계수 $(\mathrm{CC})$ : (a) 경우 1 에 대한 $\mathrm{IE},(\mathrm{b})$ 경우 1 에 대한 $\mathrm{CC},(\mathrm{c})$ 경 우 2 에 대한 $\mathrm{IE},(\mathrm{d})$ 경우 2 에 대한 $\mathrm{CC},(\mathrm{e})$ 경우 3 에 대한 $\mathrm{IE},(\mathrm{f})$ 경우 3 에 대한 $\mathrm{CC} . \mathrm{GN}(\square)$ 과 GNPI (- $\mathrm{O}$ ). 조 정인자, $\alpha=1 \times 10^{-8}$ (굵은 선)과 $\alpha=1 \times 10^{-9}$ (점선). 
method.

The reconstructed images with multi targets for case 2 are shown in figure 4 . The first and second rows in figure 4 show the reconstructed images after 10 iterations using the GN and GNPI methods, respectively, with different regularization parameters. In the first and second columns of the reconstructed images by both methods, all of the five targets could not be distinguished with the higher regularization parameter. However, when the regularization parameter decreases, the five targets are visible but the background neighbor pixels of target have irregular resistivity values in the GN image of figure $4(\mathrm{~d})$. On the other hand with the GNPI method in figure 4(e), the target locations are estimated with good accuracy.

The reconstructed images for case 3 are shown in figure 5. The reconstructed images are shown in the first and second rows after 10 iterations using the GN and GNPI methods, respectively, with different regularization parameters. With the higher regularization parameter, two targets near the center of the domain are missing in figures 5(b) and 5(e). However, with the lower regularization parameter in the third column, the seven targets are reconstructed by the GN and GNPI methods. Figure 5(d) shows the locations of the seven targets but the estimated values of the background resistivity distribution are lower compared to the true ones of that. However, in the GNPI image of figure $5(\mathrm{~g})$, seven targets are distinguishable clearly with flat background resistivity distribution. Furthermore, the target and background resistivity distributions estimated by the proposed method are close to the true ones compared to the GN method. Similar to the results of cases 1 and 2, the proposed method estimates the positions of the multi targets with good accuracy and has good resolution.

In figure 6 , the condition numbers in two inverse algorithms are shown according to the iteration number for cases 1 to 3 . The lines $\square$ and $-\bullet$ correspond to the condition numbers in the GN and GNPI methods, respectively. The solid and dashed lines correspond to the regularization parameters, $\alpha=1 \times 10^{-8}$ and $\alpha=1 \times 10^{-9}$, respectively. From figure 6 , it can be noticed that the condition number of the GNPI method is smaller than that of the GN method for all cases. This means the proposed scheme has contributed to diminishing the ill-posedness in the ERT inverse problem.

In order to evaluate the reconstruction performance of the inverse algorithms, the relative image error (IE) and the correlation coefficient (CC) between true and estimated resistivity vectors are used[18]

$$
\begin{aligned}
& \mathrm{IE}=\frac{\|\rho-\hat{\rho}\|}{\|\rho\|} \\
& \mathrm{CC}=\frac{\sum_{j=1}^{N}\left[\left(\rho_{j}-\bar{\rho}\right)\left(\hat{\rho}_{j}-\overline{\hat{\rho}}\right)\right]}{\sqrt{\sum_{j=1}^{N}\left(\rho_{j}-\bar{\rho}\right)^{2} \sum_{j=1}^{N}\left(\hat{\rho}_{j}-\overline{\hat{\rho}}\right)^{2}}}
\end{aligned}
$$

where $\rho$ and $\hat{\rho}$ are the true and estimated resistivity vectors, respectively, and $\bar{\rho}$ and $\overline{\hat{\rho}}$ are the mean values of $\rho$ and $\hat{\rho}$, respectively. It should be noticed that smaller IE and bigger $\mathrm{CC}$ values correspond to better reconstruction performance.

Figure 7 shows the $\mathrm{IE}$ and $\mathrm{CC}$ plots according to the iteration number for cases 1 to 3 . The lines $\square$ and - correspond to the GN and GNPI methods, respectively. As expected from the reconstructed images in figure 2 to figure 4 , the GNPI method has smaller and bigger values for the given regularization parameter in the $\mathrm{IE}$ and $\mathrm{CC}$ plots, respectively, which means the proposed method gives better reconstruction performance compared to the GN method.

\section{Conclusions}

This paper is concerned with reducing the condition number and diminishing the ill-posedness, and therefore enhancing the spatial resolution in the ERT inverse problem. In this paper, prior knowledge of the homogeneous data is employed to improve the spatial resolution of the conventional Gauss-Newton method in two-phase flow fields. Moreover, image segmentation is used to extract the background elements from the target elements and to make more uniform distribution in the background regions. Numerical experiments were carried out to evaluate the reconstruction performance of the proposed method. After prior 
information and image segmentation are implemented into the image reconstruction, improved results are obtained with the aid of the proposed scheme compared to the conventional Gauss-Newton method.

\section{References}

[1] F. A. Holand, R. Bragg, Fluid Flow for Chemical Engineers, Edward Arnold Publisher, 1995

[2] O. C. Jones, J. T. Lin, L. Ovacik, H. Shu, "Impedance imaging relative to gas-liquid systems," Nuclear Engineering and Design, Vol.141, pp.159-176, 1993

[3] K. Y. Kim, B. S. Kim, M. C. Kim, S. Kim, Y. J. Lee, H. J. Jeon, B. Y. Choi, M. Vauhkonen, "Electrical impedance imaging of two-phase fields with an adaptive mesh grouping scheme," IEEE Transactions on Magnetics, Vol.40, pp.1124-1127, 2004

[4] M. Cheney, D. Isaacson, J. C. Newell, S. Simske, J. Goble, "NOSER: An algorithm for solving the inverse conductivity problem," International Journal of Imaging Systems and Technology, Vol.2, pp.66-75, 1990

[5] B. S. Kim, A. K. Khambampati, S. Kim, K. Y. Kim, "Image reconstruction with an adaptive threshold technique in electrical resistance tomography," Measurement Science and Technology, Vol.22, pp.1-12, 2011

[6] N. Otsu, "A threshold selection method from gray-level histograms," IEEE Transactions on Systems, Man, and Cybernetics, Vol.9, pp.62-66, 1979

[7] M. Vauhkonen, Electrical impedance tomography and prior information, Ph.D. Thesis, University of Kuopio, Finland, 1997

[8] D. K. Han, A. Prosperetti, "A shape decomposition technique in electrical impedance tomography," Journal of Computational Physics, Vol.155, pp.75-95, 1999

[9] V. Kolehmainen, A. Voutilainen, J. P. Kaipio, "Estimation of non-stationary region boundaries in EIT-state estimation approach," Inverse Problems, Vol.17, pp.1937-1956, 2001

[10] M. C. Kim, K. Y. Kim, S. Kim, "Estimation of phase boundaries in two-phase systems by an electrical impedance tomography technique," Journal of Industrial and Engineering Chemistry, Vol.10, pp.710-716, 2004

[11] M. C. Kim, K. Y. Kim, S. Kim, "Two-phase visualization by electrical impedance tomography with prior information," Korean Journal of Chemical Engineering, Vol.20, pp.601-608, 2003

[12] L. M. Heikkinen, R. M. West, M. Vauhkonen, "Utilizing prior information in the estimation of volume fraction distribution," International Journal for Numerical Methods in Engineering, Vol.64, pp.1719-1740, 2005

[13] P. Hua, E. J. Woo, J. G. Webster, W. J. Tompkins, "Iterative reconstruction methods using regularization and optimal current patterns in electrical impedance tomography," IEEE Transactions on Medical Imaging, Vol.10, pp.621-628, 1991

[14] M. Vauhkonen, D. Vadasz, P. A. Karjalainen, E. Somersalo, J. P. Kaipio, "Tikhonov regularization and prior information in electrical impedance tomography," IEEE Transactions on Medical Imaging, Vol.17, pp.285-293, 1998

[15] E. Somersalo, M. Cheney, D. Isaacson, "Existence and uniqueness for electrode models for electric current computed tomography," SIAM Journal on Applied Mathematics, Vol.52, pp.1023-1040, 1992

[16] J. G. Webster, Electrical Impedance Tomography, IOP Publishing Ltd, 1990

[17] W. R. B. Lionheart, "EIT Reconstruction algorithms: pitfalls, challenges and recent developments," Physiological Measurement, Vol.25, pp.125-142, 2004

[18] W. Q. Yang, L. Peng, "Image reconstruction algorithms for electrical capacitance tomography," Measurement Science and Technology, Vol.14, R1-R13, 2003 


\section{BIOGRAPHY}

Bong Seok Kim (Member)

1999 : BS degree in Electronic
Engineering, Jeju National
University.
$2001:$ MS degree in Electronic
Engineering, Jeju National
University.
$2006: \mathrm{PhD}$ degree in Electronic

Engineering, Jeju National University.

2009 2013 : Research Professor, Institute for Nuclear

Science and Technology, Jeju National University.

2014 : Research Professor, Clean Energy

Convergence and Integration Center for Human

Resources Training and Education, Jeju National

University

\section{Sin Kim (Member)}

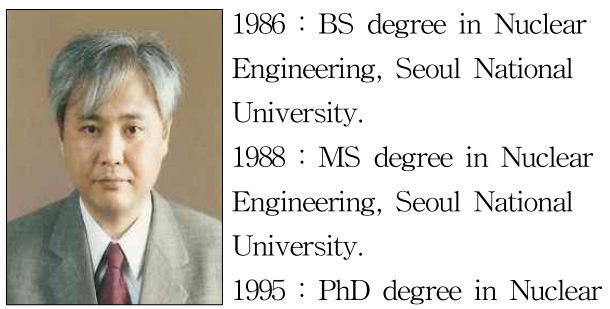

Engineering, Seoul National University.

1996 2014 : Professor, Dept. of Nuclear and Energy

Engineering, Jeju National University.

\section{Kyung Youn Kim (Member)}

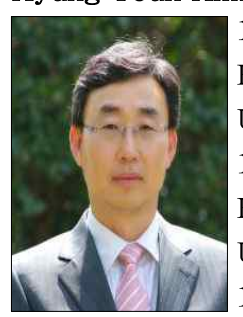

1983 : BS degree in Electronic

Engineering, Kyungpook National

University.

1986 : MS degree in Electronic

Engineering, Kyungpook National

University.

1990: PhD degree in Electronic

Engineering, Kyungpook National University.

1990 2014 : Professor, Dept. of Nuclear and Energy

Engineering, Jeju National University. 